\title{
Proceeding
}

7th INSHS International Christmas Sport Scientific Conference, 9-12 December 2012. International Network of Sport and Health

Science. Szombathely, Hungary

\section{Futsal training by videoanalysis}

\author{
LORIS POLIDORO , FABIO BIANCHI, PIO ALFREDO DI TORE, GAETANO RAIOLA
}

Department of Human, Philosophical and Education Sciences (DISUFF) University of Salerno, Italy

\begin{abstract}
Polidoro L, Bianchi F, Di Tore PF, Raiola G. Futsal training by videoanalysis. J. Hum. Sport Exerc. Vol.8, No. Proc2, pp. S290-S296, 2013. "Five-a-side soccer", also known as Futsal, originated in Uruguay in 1930. In South America it is known as futbol de salon, that is, indoor soccer. The official international denomination is Futsal which is coined from two words: futbol (soccer) and salon (a hall or covered place). In the Futsal, one of the most important variables to execute an effective action, it is the time needed by the athlete to complete his own movement (Nicoletti et al., 2007). Futsal is beneficial in developing motor skills unique to the technical characteristics of the game, such as the rules and the field of play for which the time to analyze, evaluate, elaborate, and execute is limited when compared to other team sports (Schmidt et al., 2000). Futsal is particularly adapted for children, ages 8-10 years, (Winter, in: Meinel et al., 1984) who are learning the specific techniques of play. For this reason, the Italian Soccer Federation (F.I.G.C.) has instituted futsal schools and has mandated Soccer 5 in its own basic programs. Furthermore, quality motor skills may be learned (Sanders et al., 2004 and Bandura, 1997) if they are included in the weekly instructional program. The purpose of the pilot study is to verify whether members of a sample are better at learning specific techniques (Menichelli, 2010), as compared to a control group, when the sample players watch and review videotaped actions or skills taken of the video recorded while they practice or video or a motor skills module. In the study protocol, 20 players practice twice a week for one year. But only 10 players view training videos before each practice. The two groups have the same technical characteristics (homogeneous). Each group is tested at the beginning, during, and at the end of the study on three techniques of the game, selected from fundamentals of play: 1. Control of the ball: oriented ball control with the bottom foot (called "stop by sole" or "sole control"); 2 . Driving the ball: moving the ball with the sole; 3 . Shooting: tip shoot. Two experts and the highly skilled sample player evaluate the videotape together. Statistical evaluation is done using multiple regression analysis of the curves of the two groups. Significant increases in the execution of the techniques of play should be found in the videotaped sample group and should lead to an in-depth study with a larger study sample. Eventually, positive findings of the hypothesis, would suggest video analysis to be included in training programs as an educational and evaluation tool. Key words: PERFORMANCE ANALYSIS, COACHING METHODOLOGY, FUTSAL, TECHNICAL DEVELOPMENT, YOUNG PLAYERS.
\end{abstract}

Corresponding author. Raiola, Via Berenice 11, Napoli, Italy.

Email: raiolagaetano@libero.it

7th INSHS International Christmas Sport Scientific Conference, 9-12 December 2012. International Network of Sport and Health Science. Szombathely, Hungary.

JOURNAL OF HUMAN SPORT \& EXERCISE ISSN 1988-5202

(c) Faculty of Education. University of Alicante

doi:10.4100/jhse.2012.8.Proc2.31

VOLUME 8 | Proc2 | 2013 | S290 


\section{INTRODUCTION}

The "five a side soccer" was originally invented in Uruguay, where it is traditionally known as Futbol de salon. Internationally it is instead known as futsal, (Portuguese pronunciation: [fut'saw]) is a variant of association football that is played on a smaller pitch and mainly played indoors. Its name is a portmanteau of the Portuguese futebol de salão, which can be translated as "hall football" or "indoor football". It is the International Football equivalent of the US's Arena Football. During the sport's second world championships held in Madrid in 1985, the name Fútbol Sala was used. Since then, all other names have been officially and internationally changed to futsal.

Futsal was created in 1933, when a professor from ACM Montevideo, Juan Carlos Ceriani Gravier, needed his students to play soccer using hockey or basketball courts. His goal was to invent a team sport feasible for indoor and outdoor facilities, utilizing existing numerous basketball courts, which could resemble the traditional soccer that was very popular after Uruguay national team won the World Cup in 1930 and the Olympic games in 1924 and 1928.

The first Italian translation of futsal was essentially "calcetto" as suggested by some Italian teams like "Marino Calcetto", winner of the Italian league in 1986/87 and BNL Calcetto. Later, with the advent of FIFA and the creation of five-football, which gradually became known as futsal, in Italy it was called "Calcio a 5".

In recent years, in Italy it is spreading the habit to use the word "futsal" to refer to"Calcio a 5" (FIFA). Instead, the "futbol de salon", sport run by the AMF, is referred to as "indoor soccer". In Futsal, one of the most important variables for the effectiveness of the game-play is the amount of time required by an athlete to make its move (Nicoletti \& Borghi, 2007). In fact, Futsal is particularly suited to the development of motor skills in their technical, space and rules of the game where the time of analysis, evaluation, processing and execution is limited compared to other team-sports (Schmidt et al., 2000) and it may be particularly suited for children at age of 8-10 years (Winter, in: Meinel et al., 1984) to acquire game-specific techniques. Therefore, the Italian Soccer Federation (FIGC) has made it mandatory for their "Serie A" sport clubs, basic activities of futsal by establishing Schools of Futsal. In addition, motor imagery induced by playing futsal (Sanders et al., 2004; Bandura, 1997) can enhance quality-motor learning if practiced on weekly basis.

The purpose of a pilot study is to establish whether a sample group of players, who are asked to regularly watch video recordings of their own games or motor performance patterns, can improve learning capabilities of specific techniques (Menichelli, 2010) compared to the a control-group which has not been subjected to view such videos. Too often now, the new scientific discoveries do not translate into innovation in everyday life. This is even more true if you consider the motor-sport field, where rules and game-play are not based on scientific assumptions, but based on personal experiences or long standing practices. This gap, that we may call "post-discovery", is the space in which we're going to place our research work, which consists of translating recent neuro-cognitive-learning discoveries into practice-methodology for teaching sports in the juvenile context, also to provide an operational model to analyze and evaluate the quality of technical learning. In the world of youth football it is common to use some simple technical and tactical tests to make valid and reliable determinations to be included in the overall process of programming and allow proper monitoring of individual learning paths for those undergoing the evaluation.

In Futsal, likewise other sports, the athlete's technical skills are considered mostly rely on innate capabilities and not easily modifiable by learning, especially in experienced players. Therefore, the work in the youth sector is very important because the play experience in children is still limited and evolving. From 
reviewing existing literature in this regard, there are no significant studies concerning the application of ideo-motor training in children and the assessment through the performance analysis of the learning process in this age group.

How can we improve the learning process? How can we possibly measure the skills improvement? We will try to address these questions analyzing case-studies such as learning of basic technical gestures in the sport of football-5 during the annual program for a group of 20 children in the age group 9-10 years-old, a category called "Chicks", with bi-weekly practice plan.

\section{MATERIAL AND METHODS}

\section{Participants}

Pre-teens $9-10$ years-old organized by the coach in two homogeneous groups (sample group $n=10$, control group $n=10$ - Figure 1). All the young players have practiced futsal from one or two years with the same team.

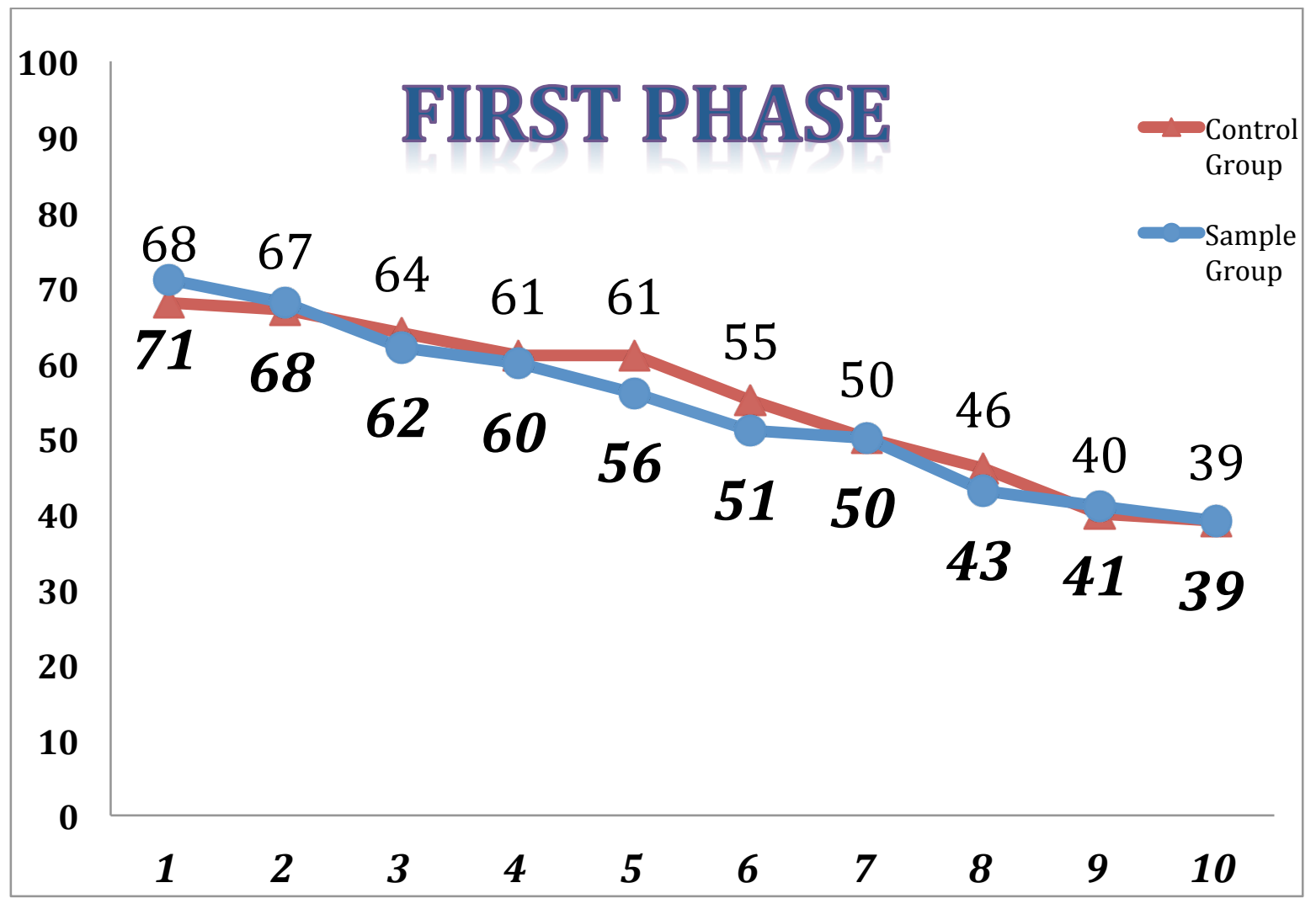

Figure 1. First Phase: Analysis of pre-assessment of the habilitation capabilities for checking homogeneity of the groups.

Search Method - Structure of the project

The research study is divided into three phases:

- In the first phase (input), we conducted a pre-assessment of the habilitation capabilities through some basic technical tests on fundamentals (Table1: control of the ball with oriented sole, shooting the ball with the tip and run the ball with the sole). 
- In the second phase, which lasts the entire tournament-year (nine months), the sample group ( $\mathrm{n}=$ 10) is involved in watching video-recorded technical gestures executed by a professional futsal player (Italian National Under-21). During this phase, we will verify and assess the evolution of technical learning (ongoing).

- In the last phase, we will evaluate the two teams to understand and describe the incisiveness of the learning methodology object of this study. Such assessment will be done by the same professional player (model), by filling out specific assessment sheets during the observation of the students as they perform the three predetermined technical gestures.

\section{Executive proceedings}

The sample group will meet at the sports facility 30 minutes before the control group. The team will be exposed to the video projection of three technical gestures, chosen from the game fundamentals:

1. Control of the ball: oriented ball control (to left and to right side) with the bottom foot (called "stop by sole").

2. Driving the ball, moving the ball with the sole.

3. Shooting: tip shoot.

The prearranged video clips are presented by the trainer, mainly focusing on the body segments relations and the most common execution mistakes. The first 5 minutes will be devoted to relaxation by listening to relaxing music and projected images, as the kids come to the field with a very high emotional charge that could adversely affect their ability to concentrate and focus. The next step is based on playing the video footage of the technical model in its entirety, inviting children to their highest attention while watching the video-clips in order to catch and learn as much information as possible. The last 5 minutes will be devoted to students. They will be asked to close their eyes and imagine themselves in executing the same gestures observed in the video. At the end of this phase, the sample group will begin the entire workout with the rest of the group, namely the control group, in such a way as not to jeopardize the technical-educational program of the entire team.

\section{Hypothesis and objectives}

The assumptions and objectives of this research are the following:

- Describe how a child's learning process is affected by practicing basic technical movements proposed with a mix of traditional training, based on repetition of gestures, as well as "ideo-motor" training, which is based on the observation of videos of technical gestures executed by a professional player (model).

- Identify when / how the ideomotor training impacts on the learning process, thus allowing to study the individual's technical skill enhancements, object of this research.

- The students' capability of self-assessment will be improved by the acquisition of skills of observation and self-observation of motor gestures, either online (immediately after an execution) and offline (by video recording and observing themselves while performing the gestures).

- The tests proposed in this study are specifically structured to evaluate accuracy and/or correctness of gesture executions expressed by young athletes, in relation to the basic football skills such as "oriented sole control" (to left and to right side), driving the ball with the sole and shoot tip (typical gestures of this discipline). 
Table 1. FIRST PHASE: Pre-assessment of the habilitation capabilities in sample group and control group.

\begin{tabular}{|c|c|c|c|c|c|c|c|c|c|c|c|c|c|c|c|c|c|c|c|c|}
\hline \multirow{2}{*}{$\begin{array}{l}\text { hnical } \\
\text { stures } \\
\text { criptor }\end{array}$} & \multicolumn{5}{|c|}{ Oriented sole control to left side } & \multicolumn{5}{|c|}{ Oriented sole control to right side } & \multicolumn{5}{|c|}{ Shoot tip } & \multicolumn{5}{|c|}{$\begin{array}{c}\text { Driving the ball: moving the ball with the } \\
\text { sole }\end{array}$} \\
\hline & Dominan & Workin & Suppor & Trun & Arm & Dominan & Workin & Suppor & Trun & Arm & Dominan & Workin & Suppor & Trun & Arm & Dominan & Workin & Suppor & Trun & Arm \\
\hline \multirow[t]{2}{*}{$\mathbf{s}$} & $\begin{array}{c}t \\
\text { foot }\end{array}$ & $\begin{array}{c}\mathrm{g} \\
\mathrm{leg}\end{array}$ & $\begin{array}{c}t \\
\text { leg }\end{array}$ & k & $\mathrm{s}$ & $\begin{array}{c}t \\
\text { foot }\end{array}$ & $\begin{array}{c}\text { g } \\
\text { leg }\end{array}$ & $\begin{array}{c}t \\
\text { leg }\end{array}$ & k & $\mathrm{s}$ & $\begin{array}{c}t \\
\text { foot }\end{array}$ & $\begin{array}{l}\text { g } \\
\text { leg }\end{array}$ & $\begin{array}{c}t \\
\text { leg }\end{array}$ & k & $\mathrm{s}$ & $\begin{array}{c}t \\
\text { foot }\end{array}$ & $\begin{array}{c}\text { g } \\
\text { leg }\end{array}$ & $\begin{array}{c}\mathrm{t} \\
\mathrm{leg}\end{array}$ & k & $\mathrm{s}$ \\
\hline & 4 & 3 & 3 & 4 & 3 & 3 & 3 & 4 & 4 & 3 & 3 & 2 & 4 & 3 & 3 & 3 & 4 & 4 & 4 & 4 \\
\hline \multirow[t]{2}{*}{ er 2} & 2 & 3 & 3 & 3 & 4 & 3 & 2 & 3 & 3 & 4 & 4 & 3 & 4 & 4 & 4 & 3 & 4 & 5 & 3 & 3 \\
\hline & 3 & 4 & 4 & 3 & 3 & 2 & 4 & 4 & 3 & 3 & 4 & 2 & 2 & 4 & 3 & 3 & 2 & 4 & 4 & 3 \\
\hline \multirow[t]{2}{*}{ er 4} & 3 & 2 & 3 & 2 & 3 & 4 & 3 & 3 & 4 & 4 & 2 & 2 & 4 & 3 & 2 & 3 & 3 & 3 & 4 & 4 \\
\hline & 3 & 3 & 3 & 3 & 2 & 3 & 3 & 3 & 4 & 3 & 2 & 4 & 3 & 3 & 2 & 3 & 4 & 3 & 4 & 3 \\
\hline \multirow[t]{2}{*}{ er 6} & 3 & 3 & 4 & 2 & 4 & 3 & 3 & 3 & 2 & 3 & 2 & 2 & 3 & 2 & 3 & 2 & 3 & 3 & 3 & 2 \\
\hline & - & 2 & 3 & 3 & 2 & 3 & 3 & 3 & 3 & 3 & 3 & 3 & 2 & 3 & 2 & 2 & 2 & 3 & 3 & 2 \\
\hline \multirow[t]{2}{*}{ er 8} & 2 & 3 & 3 & 3 & 2 & 1 & 2 & 2 & 2 & 2 & 1 & 3 & 3 & 3 & 3 & 1 & 2 & 3 & 3 & 2 \\
\hline & 1 & 1 & 3 & 1 & 2 & 1 & 2 & 3 & 2 & 1 & 3 & 3 & 2 & 2 & 2 & 2 & 2 & 3 & 2 & 2 \\
\hline er 10 & - & 2 & 2 & 2 & 2 & 2 & 2 & 2 & 2 & 1 & 3 & 3 & 2 & 3 & 3 & 1 & 1 & 2 & 2 & 2 \\
\hline \multicolumn{21}{|l|}{ er 1} \\
\hline er 2 & 4 & 3 & 4 & 4 & 3 & 3 & 2 & 4 & 3 & 3 & 5 & 3 & 5 & 4 & 2 & 4 & 4 & 4 & 2 & 2 \\
\hline \multicolumn{21}{|l|}{ er 3} \\
\hline er 4 & 3 & 3 & 4 & 3 & 3 & 1 & 3 & 3 & 3 & 3 & 1 & 3 & 3 & 3 & 2 & 3 & 4 & 4 & 4 & 4 \\
\hline \multicolumn{21}{|l|}{ er 5} \\
\hline er 6 & 2 & 3 & 2 & 3 & 2 & 1 & 3 & 2 & 3 & 3 & 3 & 3 & 2 & 3 & 4 & 2 & 2 & 3 & 3 & 2 \\
\hline \multicolumn{21}{|l|}{ er 7} \\
\hline er 8 & 1 & 2 & 3 & 3 & 3 & 2 & 2 & 2 & 2 & 1 & 2 & 3 & 2 & 2 & 2 & 1 & 2 & 3 & 2 & 3 \\
\hline \multicolumn{21}{|l|}{ er 9} \\
\hline er 10 & - & 2 & 2 & 2 & 2 & 2 & 2 & 2 & 2 & 1 & 3 & 3 & 2 & 3 & 3 & 1 & 1 & 2 & 2 & 2 \\
\hline
\end{tabular}


In this research, another important aspect is the motivations provided to young athletes, aiming to achieve the maximum effort in terms of concentration, focus and short and intense commitment.

\section{RESULTS}

The expected results are the following:

1. The use of ideo-motor learning as a methodology is more effective in the technical development of young players in the age group between $9-10$ years old;

2. A more rapid and correct acquisition of technical gestures by the kids part of the sample group in relation to the control group;

3. Video recording and reviewing gestures is a suitable tool for evaluating of motor execution. It is also an analysis methodology that help to identify the most common mistakes and their correction by a qualified trainer.

4. Improved ability in self-assessment and self-correction by the kids part of sample group, acquiring the tendency to imagine a point of observation outside in a dynamic form.

\section{DISCUSSION, CONCLUSIONS AND FUTURE PROSPECTS}

Too often, the process of teaching and learning is taken for granted, inevitable and considered automatic when a person shows to another what he knows. The scientific evidence shows that this simplistic approach most of times undermines the efforts of educators, indeed it generates frustration in students, making both parties unhappy. Here, once again, the virtuous circle theory-practice-theory can prove to be a winning, making the learning process engaging and fascinating at the same time.

This research aims to provide a valuable tool and a starting point for coaches and scholars of learning process in the field of youth sports. The results show how this study can help the trainer with coaching the team in refining and analyzing their technical skills in a different and original way, by creating a set of methods that help improve consciously learning the technical fundamentals, specific to a sports such as Futsal.

The inclusion of video analysis, as a methodological approach for educational purposes, in the technical training program, can also stimulate the self-assessment of the young student, to be considered the true starting point for the correct construction of the technical-motor skills.

The small size of our sample/control group does not allow us to generalize the results in statistical terms. However, it certainly lays the foundation of observation for research development on a much larger scale and representative.

\section{REFERENCES}

1. BANDURA A. Self-efficacy: exercise of control, New York: Freeman. It. Tr. (2000) Autoefficacia: teoria e applicazioni, Trento, Italy: Erickson. 1997.

2. MEINEL K, SCHNABEL G. Teoria del movimiento. Società Stampa Sportiva, Roma. 1984.

3. MENICHELLI R. Guida Tecnica per le Scuole Calcio a 5, FIGC-LND. 2010.

4. NICOLETTI R, BORGHI AM. II controllo motorio. II Mulino, Bologna. 2007.

5. HUGHES M, TAVARES F. Notational Analysis of Sport - IV. Porto: Faculty of Sports Sciences and Education Portugal. 2001. 
6. HUGHES M, BARTLETT R. Special edition on performance analysis. Journal of Sports. 2002.

7. RAIOLA G. Motor learning and didactics into physical education and sport documents in middle school-first cycle of education in Italy. Journal of Physical Education and Sport. 2012 12(2):157163

8. RIZZOLATTI G. So quel che fai. II cervello che agisce e i neuroni specchio. Raffaello Cortina Editore, Milano, Italia. 2006.

9. SANDERS CW, SADOSKI M, et al. Comparing the effects of physical practice and mental imagery rehearsal on learning basic surgical skills by medical students. 2004.

10. SCHMIDT RA, WRISBERG CA. Apprendimento motorio e prestazione. Dai principi alla pratica. Società Stampa Sportiva, Roma. 2000. 